\title{
Beyond Islet Transplantation in Diabetes Cell Therapy: From Embryonic Stem Cells to Transdifferentiation of Adult Cells
}

\author{
M.C. Gioviale, M. Bellavia, G. Damiano, and A.I. Lo Monte
}

\begin{abstract}
Exogenous insulin is, at the moment, the therapy of choice of diabetes, but does not allow tight regulation of glucose leading to long-term complications. Recently, pancreatic islet transplantation to reconstitute insulin-producing $\beta$ cells, has emerged as an alternative promising therapeutic approach. Unfortunately, the number of donor islets is too low compared with the high number of patients needing a transplantation leading to a search for renewable sources of high-quality $\beta$-cells. This review, summarizes more recent promising approaches to the generation of new $\beta$-cells from embryonic stem cells for transdifferentiation of adult cells, particularly a critical examination of the seminal work by Lumelsky et al.
\end{abstract}

$\mathbf{T}$ HE GOAL OF therapy of type 1 diabetes (DM-1) is to restore a glycometabolic picture as close as possible to normal. Because the cause of DM-1 is failure to produce insulin owing to destruction of $\beta$-pancreatic cells, the therapy is replacement of lost endocrine function. Since 1921, when Nicolae Constantin Paulescu, was able to cure diabetes with insulin, which he called Pancreina, most patients undergo replacement therapy with exogenous insulin. There has been a search for a permanent diabetes 'cure' that replaces $\beta$-pancreatic cells, freeing patients from insulin requirements.

The radical solution is whole pancreas transplantation, a surgical procedure developed in the last 10 years. It has success rates comparable to those of other organ transplantations: $80 \%$ of patients achieve and maintained insulin independence for $>6$ to 8 years. ${ }^{1}$ However, pancreas transplantation is a challenging procedure, requires a significant immunosuppressive therapy to prevent organ rejection, ${ }^{2,3}$ and therefore, is performed only in combination with a kidney transplantation in diabetic dialysis patients with end-stage renal disease. ${ }^{4}$ Unfortunately, this intervention is not without complications. ${ }^{5}$ Also, xenotransplantation has received attention in the past, but implies serious problems of health surveillance. ${ }^{6,7}$ In the last few years islet transplantation has proffered an alternative promising therapy. Recently, experimental approaches using stem cell administration, transdifferentiation of ductal cells, or genetic reprogramming seem the future of diabetes therapy.
PANCREATIC ISLET TRANSPLANTATION General Considerations

The islets of Langerhans are clusters of endocrine cells that constitute about $1 \%$ of pancreatic tissue where they sense blood glucose levels, secreting hormones to regulate them. Pancreatic islets for transplantation have been prepared by an isolation procedure, developed by Ricordi, which combines mechanical disruption and enzymatic digestion, followed by purification through gradients of varying density (Ricordi Chamber) (Table 1). ${ }^{8}$

The possibility to culture pancreatic islets offers a range of therapeutic opportunities to improve efficiency and graft survival. This procedure, which is much simpler than vascularized pancreas transplantation, is associated with a low morbidity and can be repeated to infuse additional islet doses to achieve adequate metabolic control and insulin independence.

The first islet transplantations performed in immunosuppressed patients with DM-1 were characterized by a low

From the Transplant Unit (M.C.G., M.B., G.D., A.I.L.M.), AOUP "P. Giaccone", School of Medicine, Università degli Studi di Palermo, Palermo, Italy; Dipartimento di Discipline Chirurgiche ed Oncologiche (A.I.L.M.), School of Medicine, School of Biotechnology, Università degli Studi di Palermo, Italy.

Attilio Ignazio Lo Monte, Associate Professor of General Surgery, Transplant Unit, AOUP "P. Giaccone" Università degli Studi di Palermo, Dipartimento di Discipline Chirurgiche ed Oncologiche Via del Vespro 129, 90127 Palermo, Italy. E-mail: attilioignazio. lomonte@unipa.it 


\section{Table 1. Procedure for Isolation of Pancreatic Islets}

Pancreatic islet cells are obtained from multi-organ donors after separation from the tissue surrounding the gland.

The Wirsung duct is cannulated to allow injection of a solution containing collagenase in order to relax the organ and enable the achievement of an effective enzyme activity during the dissociation.

The gland is then divided into several parts and transferred to the dissociation chamber, consisting of a lower portion, where the pancreas is inserted together with metal balls, and an upper portion consisting of an inverted funnel, separated by a porous metal filter with a specific porosity.

The digestion process is the combination of the enzymatic effect (obtained by increasing the temperature) and mechanical (generated by the action of the ball during the stirring of the room) that results in the release of fragments of the pancreas that can pass through the filter metal due to the unidirectional flow of liquid dissociation.

The digested pancreas is then purified by using different density gradients (continuous and discontinuous) to enrich the endocrine component.

The islets that make up only $1 \%$ of pancreatic tissue can be viewed using a dye that gives it a distinctive red color.

After the purification, enriched fractions containing levels of purity can be obtained.

success rate, both in terms of insulin independence and recovery of C-peptide secretion, owing to the inconsistent quality of the transplanted islets and the inadequate immunosuppression. ${ }^{9}$ The revival of this procedure occurred with the development of an innovative immunosuppressive scheme, the 'Edmonton Protocol', which was applied in selected centers worldwide to reproducibly obtain highquality islets. ${ }^{10,11}$ Although initial results were excellent with a 1-year success rate of almost $100 \%$, continued experience revealed them to decrease dramatically at 2 to 3 years. However the extraordinary initial data stimulated research in the field of $\beta$-cell replacement.

\section{STEM CELLS: A SOURCE FOR NEW $\beta$-CELLS} Pancreatic Stem Cells

The postnatal pancreatic duct may harbor islet precursor/ stem cells because of specific cellular migration during embryonic development. ${ }^{12}$ Islet neogenesis, the generation of new islets from pancreatic stem/progenitor cells located in the ducts, could be an active process in the postnatal pancreas. Interestingly insulin-producing cells have been generated from adult pancreatic ductal tissues in vitro. ${ }^{13-18}$ Fluorescent activated cell sorting, which characterizes human $\beta$-cells through detection of CD95, ${ }^{19,20}$ may be a promising technique to isolate multipotent pancreatic progenitors from neonatal and adult pancreata. By combining flow cytometry and clonal analysis, ${ }^{21,22}$ some authors have described molecular markers including hepatocyte growth factor (HGF) c-Met expressed specifically on pancreatic stem/progenitor cells candidate. Moreover, they have identified a new specific marker for ductal cells CD133. ${ }^{22}$
The use of adult stem cells isolated from patients could solve immunologic problems associated with cell transplantation. Unfortunately, adult stem cells are rare and difficult to expand in culture. In contrast, new generation of $\beta$-cells after birth, has been reported from existing cells, and not putative pancreatic stem cells. ${ }^{21}$ Insulin-producing $\beta$-cells have also been produced from endogenous endocrine progenitors after injury. ${ }^{22}$ The existence of adult pancreatic stem/progenitor cells and their ability to proliferate in response to particular stimuli requires more investigations.

Stem Cells of Non-pancreatic Origin: Is Lumelsky's Protocol Free From Inconsistencies?

Recent studies have demonstrated that embryonic stem cells (ESCs) ${ }^{23-25}$ induced pluripotent stem cells, ${ }^{26,27}$ and adult stem cells from bone marrow (BM), ${ }^{28}$ pancreas, ${ }^{29,30}$ liver, ${ }^{31}$ umbilical cord blood, ${ }^{32}$ Wharton's jelly, ${ }^{33}$ or placenta, ${ }^{34}$ can differentiate into insulin-producing elements. Because of their high pluripotency, ESCs may be ideal for islet regeneration; obviously, their use is under debate for ethical and legal issues as well as the risks of teratoma formation. ${ }^{35}$

The seminal work regarding the potentiality of ESCs to differentiate into insulin-secreting structures similar to pancreatic islets was published by Lumelsky et al, ${ }^{23}$ who observed pancreatic islet generation from an highly enriched population of nestin-positive cells from embryoid bodies (EBs). EBs plated into serum-free medium showed negative selection for all types other than nestin-positive cells. These cells were expanded in a mitogen, basic fibroblast growth factor, in N2 serum-free medium. Mitogen withdrawal thereafter promoted cessation of cell division and differentiation. Using reverse transcription polymerase chain reaction (RT-PCR), the authors showed that these ESC expressed markers GATA-4 for visceral endoderm, HNF3b for definitive endoderm, as well as for pancreatic cells, including murine insulin I, insulin II, islet amyloid polypeptide, and the glucose transporter-2. Glucagon, a marker for the pancreatic $\alpha$ cells, was also induced in the differentiated cells. The acquisition of a pancreatic fate was confirmed by immunocytochemical analysis, which showed many strongly insulin-positive cells by the end of the processing.

The ability of ESC-derived islet-like cell clusters to survive and function in vivo was tested by grafting clusters subcutaneously into the shoulders of streptozotocin-diabetic mice. Implanted cells were vascularized, forming aggregates morphologically similar to normal pancreatic islets and remaining immunoreactive to insulin. There was no sustained correction of hyperglycemia, although the grafted animals maintained their body weights and survived longer than hyperglycemic sham-grafted controls.

Boyd et $\mathrm{al}^{36}$ raised doubts about the Lumelsky protocol. The first concern was about the interpretation of the gene expression data regarding the pancreatic markers. In fact, Boyd et al assert that it must be defined whether the gene expression was attributable to a single cell within the 
isolated cluster or whether all cells in the cluster had transcribed the genes. Furthermore, Lumelsky's data showed that "insulin-producing cell clusters" (IPCCs) had a mixed pancreatic phenotype because they contained not only $\beta$-cell but also $\alpha$-cell markers.

Another weakness in Lumelsky's protocol emerged from the quantitative PCR data, ${ }^{36}$ which demonstrated that expression of insulin-1 and insulin-2 mRNAs was consistently higher in IPCCs obtained by Blyszczuk et $\mathrm{al}^{37}$ compared with Lumelsky-generated clusters, implying that the Blyszczuk protocol produced IPCCs with superior de novo insulin-producing activity. The amylase- 2 expression in IPCCs obtained by other groups following Lumelsky's protocol $^{38}$ suggested that it may also promote exocrine differentiation; evidence not in favor of a unique $\beta$-cell phenotype acquired by ESCs. Using immunofluorescence, Rajagopal et $\mathrm{al}^{39}$ observed an attenuated relative ratio of C-peptide to insulin, suggesting that the insulin content by IPCCs was an unequal combination of de novo synthesis and adsorption from the culture medium. Most notably, however, the Blyszczuk protocol ${ }^{37}$ consistently produced the highest level of $\mathrm{C}$-peptide, indicating that it achieved superior de novo insulin synthesis. Furthermore, cell clusters obtained by Lumelsky and Blyszczuk showed prominent glucagon costaining with insulin, ${ }^{36}$ indicating that the IPCCs derived from ESCs may not represent surrogate $\beta$-cells but rather more closely resemble an $\alpha$ and $\beta$ cell hybrid Boyd et $\mathrm{a}^{40}$ proposed that glucagon/insulin costaining could alternatively indicate that IPCCs derived from ESCs were developmentally immature endocrine cells as suggested by the high expression of neurogenin-3 which, instead, is downregulated in fully mature islets. Furthermore, IPCCs seem to be defective in glucose-sensing capacity in vivo, supported by glucose stimulation assays that showed that IPCC insulin released in response to minimal glucose stimulation $(3.3 \mathrm{mmol} / \mathrm{L}$ glucose $)$ but not significantly by greater glucose stimulation $(25 \mathrm{mmol} / \mathrm{L}$ glucose $)$. In light of these issues, it seems that ESCs-based strategies to obtain pancreatic islet-like cells require further investigation.

\section{Mesenchymal Stem Cells From Adipose Tissue or Umbilical Cord: Is It a Valid Alternative to ESCs?}

An alternative to ESCs could be adipose-derived stem cells (ADSCs) because of their abundance, availability and possibility for autologous use. ${ }^{41}$ Three research groups have shown that under specific culture conditions, ADSCs differentiate into insulin, somatostatin, and glucagon-expressing or Cpeptide positive cells. ${ }^{42,43}$ Packing these cells into immunoisolation capsules to test their in vivo/in vitro functionality, Chandra et $\mathrm{al}^{44}$ reported their ability to restore normoglycemic conditions in streptozotocin-induced diabetic mice. Interestingly for the first time, this study showed that undifferentiated ADSCs exerted moderate control of blood glucose levels, leading to the speculation that the autocrine and paracrine factors of a regenerating pancreas and an hyperglycemic local diabetic micro-environment can contribute to ADSC differen- tiation. This phenomenon has also been shown for bone marrow-derived stem cells. ${ }^{45}$

Islet neogenesis has also been reported from constitutively nestin-expressing human umbilical cord matrixderived mesenchymal stem cells. Kadam et $\mathrm{al}^{46}$ reported that human placenta-derived mesenchymal stem cells (hPDMSCs) could differentiate into islet-like cells able to restore normoglycemia when transplanted under the kidney capsules of streptozotocin-induced diabetic mice. Interestingly unlike human cord blood or amnion-derived mesenchymal stem cells, the gene expression profile of undifferentiated hPDMSCs showed that they expressed mRNA for insulin, glucagon, somatostatin, Ngn3, and Isl1.

\section{Cooperation Between $\beta$-Cells and Bone Marrow: Stem Cells as a Support for Islet Function and Regeneration}

Vascularization of pancreatic islets is important for their ability to secrete insulin. Obviously, islet isolation ${ }^{47}$ breaks vascularization, which can compromise irremediably the endocrine function; a preservation method needs to counteract this deleterious effect. ${ }^{48,49}$ Endothelial cells deliver oxygen and nutrients to endocrine cells, contributing to create a microenvironment for $\beta$-cell function. In particular, they can induce insulin gene expression during islet development, stimulate $\beta$-cell proliferation, and produce a number of vasoactive, angiogenic substances, and growth factors. ${ }^{50-52}$

Hematopoietic stem cells, mesenchymal stem cells, and endothelial progenitor cells contribute to islet revascularization through vessel formation by differentiation into mature endothelial cells (EPCs) or release of pro-angiogenic factors such as HGF and vascular endothelial growth factor A. ${ }^{53-55}$ In this regard, Mathew et a ${ }^{56}$ provided evidence that bone marrow-derived EPCs, transplanted after a pancreatic injury migrate to the site of damage helping injured $\beta$-cells to recover even if they did not differentiate into insulin-producing cells.

Two other papers stress the synergism between $\beta$-cells and BM-derived cells. Sakata et $\mathrm{al}^{57}$ showed that only a combined transplantation under the kidney capsule of total BM-derived cells (not only the mesenchymal cellular fraction) with islets was able to significantly lower blood glucose levels in a streptozotocin-induced diabetes murine model. Interestingly BM-cell transplantation alone did not produce normoglycemic mice or insulin-positive cells, suggesting that direct differentiation of $\mathrm{BM}$ cells into $\beta$-cells was unlikely. Ito et $\mathrm{al}^{58}$ provided similar evidence but in this case the site of combined BM cells/islet transplantation was the liver not the kidney. BM-derived stem cells may also have a role to stimulate $\beta$-cell regeneration. ${ }^{59-61}$ For example, infusion of mesenchymal stem cells into NOD/ SCID mice increased the number of endogenous $\beta$-cells improving hyperglycemia after streptozocin-induced islet destruction. 
BEYOND STEM CELL-BASED THERAPY: TRANSDIFFERENTIATION OF ADULT CELLS TOWARD AN ISLET-LIKE PHENOTYPE

Biologic Premises

Pancreas development begins with dorsal and ventral protrusions of the primitive gut epithelium that fuse later to form the definitive organ characterized by the appearance of glucagon-producing cells. Thereafter a few insulinproducing cells appear, often co-expressing glucagon. A later step consists of a peak of endocrine cell genesis leading to numerous fully differentiated insulin-expressing $\beta$-cells and glucagon-producing $\alpha$-cells. At the end of pancreas development, endocrine cells begin to form wellorganized islets of Langerhans.

The mechanisms responsible for the development of these endocrine cell types are not fully understood, but experiments consisting of generation of mice deficient for a number of pancreatic transcription factors have helped to shed more light about them by identifying crucial mediators of organ development: Sox9, Pdx1, Ngn3, IA1, Pax4, Arx, Nkx2.2, Nkx6.1, Nkx6.2, Pax6, and MafA. ${ }^{62}$

\section{Transdifferentiation Achieved by Genetic Reprogramming Using Transcription Factors Carrying Vectors}

All pancreatic cells derive from Pdx1-expressing progenitors ${ }^{63}$ the basis of experiments to obtain pancreatic elements from other cell types. ${ }^{64-66}$ In all of these cases, adenoviral-mediated misexpression of Pdx1 in mouse liver prevented streptozotocin-induced hyperglycemia in animal models. Kaneto et $\mathrm{al}^{67}$ showed that concomitant adenoviral application of 2 factors, Pdx 1 and Ngn3 or NeuroD in the livers of mice produced transdifferentiation of hepatic cells into insulin-producing elements associated with significant amelioration of glucose tolerance.

\section{Transdifferentiation Achieved Modifying Cellular Micro- environment In Vitro}

Intriguingly, exocrine pancreatic cells have the capacity to generate their endocrine counterparts when exposed in vitro to a particular microenvironment, consisting of epidermal growth factor and leukemia inhibitory factor, agonists of the JAK2/STAT3 signalling pathway. ${ }^{68}$ We have reported our own experience in a porcine model concerning the isolation by surgical microdissection of Wirsung duct cells that, upon in vitro exposure to glucose, acquired the ability to secrete insulin and glucagon. ${ }^{18}$ Finally, it seems note worthy that human monocytes treated with macrophage colony-stimulating factor and interleukin 3 transdifferentiated into pancreatic islet-like cells in a glucosedependent manner. ${ }^{69}$

In conclusion, regenerative medicine has undergone great development in the last few years. Due to its enormous social and economic implications, diabetes cell therapy is among the most investigated branches of this field. Islet transplantation has shown significant limitations. Alternative approaches based on a full knowledge of cellular and developmental biology of pancreatic cells have been under investigation. Transdifferentiation, the process that leads an adult cell to change its phenotype, seems to be a promising approach given that adult cells are autologous, not dangerous or potentially tumorigenic, and free of the ethical implications associated with embryonic stem cells.

The transfer of the experimental results on experimental approach to increase availability of $\beta$-cells to the clinic still seems distent.

\section{REFERENCES}

1. Gruessner AC. 2011 update on pancreas transplantation: comprehensive trend analysis of 25,000 cases followed up over the course of twenty-four years at the International Pancreas Transplant Registry (IPTR). Rev Diabet Stud. 2011;13:6-16.

2. Ciancio G, Lo Monte A, Buscemi G, et al. Use of tacrolimus and mycophenolate mofetil as induction and maintenance in simultaneous pancreas-kidney transplantation. Transplant International. 2000;13:S191-S194.

3. Lo Monte AI, Ciancio G, Burke G, et al. The new immunosuppressive era. Ann Ital Chir. 1999;70:1-19.

4. Ireland R. Transplantation: effect of pancreas-after-kidney transplant on renal graft survival. Nat Rev Nephrol. 2011;26: 486-492.

5. Ciancio G, Lo Monte A, Julian JF, et al. Vascular complications following bladder drained, simultaneous pancreas-kidney transplantation: the University of Miami experience. Transplant International. 2000;13:S187-S190.

6. Lo Monte AI, Airò Farulla M, Cuccia V, et al. Il trapianto sperimentale del blocco duodeno-pancreas nel maiale. Esperienza preliminare. Large Animal Review. 2000;1:43-49.

7. Lo Monte AI, Fiasconaro M, Di Marco M, et al. Il suino come potenziale donatore multiorgano per i trapianti sull'uomo. Rischi e prospettive. Large Animal Review. 2000;1:39-42.

8. Ricordi C, Lacy PE, Finke EH, et al. Automated method for isolation of human pancreatic islets. Diabetes. 1988;37:413-20.

9. Federlin KF, Jahr H, Bretzel RG. Islet transplantation as treatment of type 1 diabetes: from experimental beginnings to clinical application. Exp Clin Endocrinol Diabetes. 2001;109: S373-83.

10. Street CN, Lakey JR, Shapiro AM, et al. Islet graft assessment in the Edmonton protocol: implications for predicting longterm clinical outcome. Diabetes. 2004;53:3107-3114.

11. Ryan EA, Lakey JR, Rajotte RV, et al. Clinical outcomes and insulin secretion after islet transplantation with the Edmonton protocol. Diabetes. 2001;50:710-719.

12. Gu G, Brown JR, Melton DA. Direct lineage tracing reveals the ontogeny of pancreatic cell fates during mouse embryogenesis. Mech Dev. 2003;120:35-43.

13. Noguchi H. Stem cells for the treatment of diabetes. Endocr J. 2007;54:7-16.

14. Noguchi H, Kaneto $\mathrm{H}$, Weir GC, et al. PDX-1 protein containing its own antennapedia-like protein transduction domain can transduce pancreatic duct and islet cells. Diabetes. 2003;52: 1732-1737.

15. Noguchi H, Matsumoto S, Ueda M, et al. Method for isolation of mouse pancreatic stem cells. Transplant Proc. 2008;40: 422-433.

16. Bonner-Weir S, Taneja M, Weir GC, et al. In vitro cultivation of human islets from expanded ductal tissue. Proc Natl Acad Sci U S A. 2000;97:7999-8004.

17. Gao R, Ustinov J, Pulkkinen MA, et al. Characterization of endocrine progenitor cells and critical factors for their differentiation in human adult pancreatic cell culture. Diabetes. 2003;52: 2007-2015. 
18. Gioviale MC, Damiano G, Montalto G, et al. Isolation and culture of beta-like cells from porcine Wirsung duct. Transplant Proc. 2009;41:1363-1366.

19. Stassi G, Todaro M, Richiusa P, et al. Expression of apoptosis-inducing CD95 (Fas/Apo-1) on human beta-cells sorted by flow-cytometry and cultured in vitro. Transplant Proc. 1995;27: 3271-3275.

20. Giordano C, Stassi G, Todaro M, et al. Autofluorescenceactivated sorting of human single beta cells and endocrine non-beta cells after enzymatic islet dissociation. Transplant Proc. 1994;26: 651-652.

21. Dor Y, Brown J, Martinez OI, et al. Adult pancreatic beta-cells are formed by self-duplication rather than stem-cell differentiation. Nature. 2004;429:41-46.

22. Xu X, D'Hoker J, Stange G, et al. Beta cells can be generated from endogenous progenitors in injured adult mouse pancreas. Cell. 2008;132:197-207.

23. Lumelsky N, Blondel O, Laeng P, et al. Differentiation of embryonic stem cells to insulin-secreting structures similar to pancreatic islets. Science. 2001;292:1389-1394.

24. D'Amour KA, Bang AG, Eliazer S, et al. Production of pancreatic hormone-expressing endocrine cells from human embryonic stem cells. Nat Biotechnol. 2006;11:1392-1401.

25. Jiang J, Au M, Lu K, et al. Generation of insulin producing islet-like clusters from human embryonic stem cells. Stem Cells. 2007;25:1940-1953.

26. Tateishi K, He J, Taranova O, et al. Generation of insulinsecreting islet-like clusters from human skin fibroblasts. $J$ Biol Chem. 2008;283:31601-31607.

27. Maehr R, Chen S, Snitow M, et al. Generation of pluripotent stem cells from patients with type 1 diabetes. Proc Natl Acad Sci U $S$ A. 2009;106:15768-15773.

28. Xie QP, Huang $\mathrm{H}, \mathrm{Xu} \mathrm{B}$, et al. Human bone marrow mesenchymal stem cells differentiate into insulin-producing cells upon microenvironmental manipulation in vitro. Differentiation. 2009; 77:483-491.

29. Noguchi H, Naziruddin B, Shimoda M, et al. Induction of insulin-producing cells from human pancreatic progenitor cells. Transplant Proc. 2010;42:2081-2083.

30. Seaberg RM, Smukler SR, Kieffer TJ, et al. Clonal identification of multipotent precursors from adult mouse pancreas that generate neural and pancreatic lineages. Nat Biotechnol. 2004;22: $1115-1124$.

31. Yang $\mathrm{L}, \mathrm{Li} \mathrm{S}, \mathrm{Hatch} \mathrm{H}$, et al. In vitro transdifferentiation of adult hepatic stem cells into pancreatic endocrine hormone producing cells. Proc Natl Acad Sci U S A. 2002;99:8078-8083.

32. Sun B, Roh KH, Lee SR, et al. Induction of human umbilical cord blood derived stem cells with embryonic stem cell phenotypes into insulin producing islet-like structure. Biochem Biophys Res Commun. 2007;354:919-923.

33. Chao KC, Chao KF, Fu YS, et al. Islet-like clusters derived from mesenchymal stem cells in Wharton's jelly of the human umbilical cord for transplantation to control type 1 diabetes. PLoS One. 2008;3:e1451-e1458.

34. Chang CM, Kao CL, Chang YL, et al. Placenta derived multipotent stem cells induced to differentiate into insulin-positive cells. Biochem Biophys Res Commun. 2007;357:414-420.

35. Lee AS, Tang C, Cao F, et al. Effects of cell number on teratoma formation by human embryonic stem cells. Cell Cycle. 2009;8:2608-2612.

36. Boyd AS, Wu DC, Higashi Y, et al. Comparison of protocols used to generate insulin-producing cell clusters from mouse embryonic stem cells. Stem Cells. 2008;26:1128-1113.

37. Blyszczuk P, Asbrand C, Rozzo A, et al. Embryonic stem cells differentiate into insulin-producing cells without selection of nestin-expressing cells. Int J Dev Biol. 2004;48:1095-1104.

38. Kitano M, Kakinuma M, Takatori A, et al. Gene expression profiling of mouse embryonic stem cell progeny differentiated by Lumelsky's protocol. Cells Tissues Organs. 2006;183:24-31.
39. Rajagopal J, Anderson WJ, Kume S, et al. Insulin staining of ES cell progeny from insulin uptake. Science. 2003;299:363-368.

40. Gradwohl G, Dierich A, LeMeur M, et al. neurogenin3 is required for the development of the four endocrine cell lineages of the pancreas. Proc Natl Acad Sci U S A. 2000;97:1607-1611.

41. Zuk PA, Zhu M, Ashjian P, et al. Human adipose tissue is a source of multipotent stem cells. Mol Biol Cell. 2002;12:4279-4295.

42. Timper K, Seboek D, Eberhardt M, et al. Human adipose tissue-derived mesenchymal stem cells differentiate into insulin, somatostatin, and glucagon expressing cells. Biochem Biophys Res Commun. 2006;341:1135-1140.

43. Lee J, Han DJ, Kim SC, et al. In vitro differentiation of human adipose tissue derived stem cells into cells with pancreatic phenotype by regenerating pancreas extract. Biochem Biophys Res Commun. 2008:375:547-551.

44. Chandra V, Swetha G, Muthyala S, et al. Islet-like cell aggregates generated from human adipose tissue derived stem cells ameliorate experimental diabetes in mice. PLoS One. 2011;6: e20615-e20627.

45. Phadnis SM, Joglekar MV, Dalvi MP, et al. Human bone marrow-derived mesenchymal cells differentiate and mature into endocrine pancreatic lineage in vivo. Cytotherapy. 2011;13:279-293.

46. Kadam SS, Bhonde RR. Islet neogenesis from the constitutively nestin expressing human umbilical cord matrix derived mesenchymal stem cells. Islet. 2010;2:112-120.

47. Lo Monte A, Maione C, Basile V, et al. Pancreatic harvesting from multiorgan donors for islet transplantation. Minerva Chir. 1996;51:759-764.

48. Gioviale MC, Damiano G, Palumbo VD, et al. Pancreatic islets from non-heart-beating donor pig: two-layer preservation method in an in vitro porcine model. Int J Artif Organs. 2011;34: $519-525$.

49. Gioviale MC, Damiano G, Cacciabaudo F, et al. A good breath of oxygen for beta-like cells obtained from porcine exocrine pancreatic tissue. Transplant Proc. 2011;43:1173-1177.

50. Zanone MM, Favaro E, Camussi G. From endothelial to beta cells: insights into pancreatic islet microendothelium. Curr Diabetes Rev. 2008;4:1-9.

51. Johansson M, Mattsson G, Andersson A, et al. Islet endothelial cells and pancreatic beta-cell proliferation: studies in vitro and during pregnancy in adult rats. Endocrinology. 2006;147: 2315-2324

52. Cabric S, Sanchez J, Johansson U, et al. Anchoring of vascular endothelial growth factor to surface-immobilized heparin on pancreatic islets: implications for stimulating islet angiogenesis. Tissue Eng Part A. 2010;16:961-970.

53. Asahara T, Murohara T, Sullivan A, et al. Isolation of putative progenitor endothelial cells for angiogenesis. Science. 1997;275:964-967.

54. Di Santo S, Yang Z, Wyler von Ballmoos M, et al. Novel cell-free strategy for therapeutic angiogenesis: in vitro generated conditioned medium can replace progenitor cell transplantation. PLoS One. 2009;4:e5643-e5648.

55. Park KS, Kim YS, Kim JH, et al. Trophic molecules derived from human mesenchymal stem cells enhance survival, function, and angiogenesis of isolated islets after transplantation. Transplantation. 2010;89:509-517.

56. Mathews V, Hanson PT, Ford E, et al. Recruitment of bone marrow-derived endothelial cells to sites of pancreatic beta-cell injury. Diabetes. 2004;53:91-98.

57. Sakata N, Chan NK, Chrisler J, et al. Bone marrow cell cotransplantation with islets improves their vascularization and function. Transplantation. 2010;89:686-693.

58. Ito T, Itakura S, Todorov I, et al. Mesenchymal stem cell and islet co-transplantation promotes graft revascularization and function. Transplantation. 2010;89:1438-1445.

59. Luo L, Badiavas E, Luo JZ, et al. Allogeneic bone marrow supports human islet beta cell survival and function over six months. Biochem Biophys Res Commun. 2007;361:859-864. 
60. Hasegawa Y, Ogihara T, Yamada T, et al. Bone marrow (BM) transplantation promotes beta-cell regeneration after acute injury through BM cell mobilization. Endocrinology. 2007;148:2006-2015.

61. Li FX, Zhu JW, Tessem JS, et al. The development of diabetes in E2f1/E2f2 mutant mice reveals important roles for bone marrow-derived cells in preventing islet cell loss. Proc Natl Acad Sci U S A. 2003;100:12935-12940.

62. Kordowich S, Mansouri A, Collombat P. Reprogramming into pancreatic endocrine cells based on developmental cues. Mol Cell Endocrinol. 2010;315:1-2.

63. Gu G, Brown JR, Melton D. Direct lineage tracing reveals the ontogeny of pancreatic cell fates during mouse embryogenesis. Mech Dev. 2003;120:35-43.

64. Ber I, Shternhall K, Perl S, et al. Functional, persistent, and extended liver to pancreas transdifferentiation. J Biol Chem. 2003; 278:31950-31957.
65. Taniguchi H, Yamato E, Tashiro F, et al. Beta-cell neogenesis induced by adenovirus-mediated gene delivery of transcription factor Pdx1 into mouse pancreas. Gene Ther. 2003;10:15-23.

66. Shternhall-Ron K, Quintana Fj, Perl S, et al. Ectopic PDX1 expression in liver ameliorates type 1 diabetes. J Autoimmun. 2007;28:134-142.

67. Kaneto H, Nakatani Y, Miyatsuka T, et al. PDX1/VP16 fusion protein, together with NeuroD or Ngn3, markedly induces insulin gene transcription and ameliorates glucose tolerance. Diabetes. 2005;54:1009-1022.

68. Baeyens L, Bouwens L. Can $\beta$-cells be derived from exocrine pancreas? Diabetes, Obesity and Metabolism. 2008;10:170-178.

69. Ruhnke M, Ungefroren H, Nussler A, et al. Differentiation of in vitro-modified human peripheral blood monocytes into hepatocyte-like and pancreatic islet-like cells. Gastroenterology. 2005;128:1774-1786. 